DOI: https://doi.org/10.14232/actahisp.2020.25.87-99

\title{
LA VELOCIDAD DE ARTICULACIÓN EN LA ENSEÑANZA DE ELE ${ }^{1}$
}

\author{
DOROTTYA KOVÁCS
}

Universidad Eötvös Loránd, Hungría

\begin{abstract}
Resumen: En la presente investigación se analiza la velocidad de articulación, es decir, la rapidez de la producción de los signos lingüísticos, en el habla semiespontánea. Comparamos la velocidad media de cuatro dialectos del español (madrileño, andaluz, mexicano y rioplatense), para tener la respuesta a la pregunta si se habla más rápidamente en Europa que en América. Además, investigamos la velocidad de articulación de estudiantes hungaroparlantes de nivel B2 para ver si sus valores son más lentos que los de los nativos, y si es necesario el desarrollo de las competencias comunicativas de los alumnos. Nuestros resultados muestran que (i) no hay una diferencia considerable entre los cuatro dialectos del español analizados, aunque el español mexicano resulta ser el más rápido; (ii) la velocidad de habla de los estudiantes húngaros es significativamente más lenta que el valor medio de la velocidad de cualquier dialecto analizado del español.
\end{abstract}

Palabras clave: dialectos, español, enseñanza de ELE, producción de habla, velocidad de articulación.

Abstract: In this paper, we analyze articulation rate in semi-spontaneous speech, that is, the velocity of the production of linguistic elements. We compare the mean rate of four dialects of Spanish (Northern Spanish, Southern Spanish, Mexican, Argentine-Uruguayan) so that we could get an answer to the question if native speakers of European Spanish speak faster than native speakers of American Spanish. Also, we investigate the articulation rate of intermediate level (B2) Hungarian students of Spanish to see if they speak more slowly than native Spanish speakers and if their communicative competences need development. Our results suggest that (i) there is no considerable difference among the four dialects of Spanish, but the Mexican Spanish seems to be the fastest dialect of the ones we analyzed; (ii) the articulation rate of the Hungarian students is significantly lower than the mean rate of all the analyzed dialects.

Keywords: Articulation Rate, Dialects, Spanish, Speech Production, Teaching Spanish.

\footnotetext{
${ }^{1}$ El presente estudio se ha realizado gracias al apoyo del "Nuevo Programa Nacional de Excelencia" ÚNKP-20-2 del Departamento Nacional de Investigación, Desarrollo e Innovación de Hungría. Quisiera darle las gracias a Kata Baditzné Pálvölgyi por sus consejos y por la ayuda que me ha dado.
} 
La velocidad de articulación en la enseñanza de ELE

\section{Introducción}

En Hungría, en las clases de español como lengua extranjera, tradicionalmente se enfatiza la enseñanza de las características morfosintácticas del español, dejando menos terreno al desarrollo de las competencias comunicativas (Baditzné, 2014: 1). Además, según la investigación de Hegedüs (2019), en las clases de la escuela primaria, por ejemplo, la comunicación en la lengua meta resulta ser muy poco frecuente entre los alumnos. Junto a estos resultados, varias investigaciones destacan la importancia de la velocidad del habla.

Así, por ejemplo, los nativos de la lengua opinan que una buena pronunciación y la presencia (y uso correcto) de marcadores discursivos pueden compensar incluso los errores gramaticales (Baditzné et al., 2018, citado por Baditzné et al., 2019). Sin embargo, los hablantes que cuentan con una pronunciación significativamente diferente de la pronunciación de los nativos son aptos solo para ejercer profesiones de menos prestigio por su falta de fluidez y rapidez, según los nativos (Baditzné, 2019).

En una investigación nuestra comparamos la velocidad de habla de estudiantes húngaros del español de nivel B2 (según el MCER) con la velocidad de un hablante nativo andaluz. Nuestros resultados mostraron que aunque los estudiantes húngaros eran hablantes cotidianos en cuanto a su velocidad en la lengua materna, al hablar español, tanto su velocidad de habla como su velocidad de articulación resultaban ser mucho más bajas que las de los nativos (Kovács, 2019). La velocidad de habla de los húngaros era de 2,66 sílabas/segundo (Kovács, 2019), mientras que la cifra media de los hablantes nativos es de 4,6-7 sílabas/segundo (Goldman-Eisler, 1968, citado por Gósy, 2004: 205).

El objetivo del presente trabajo es el análisis de la velocidad de articulación de estudiantes de nivel B2 según el MCER, comparada con el habla de nativos de cuatro dialectos del español (madrileño, andaluz, mexicano y rioplatense). En este análisis investigaremos el habla semiespontánea, es decir, entrevistas. Para el fin de esta investigación veremos hasta qué punto resulta lenta la velocidad de los húngaros y qué grado de desarrollo sería necesario en las clases de ELE. Además de encontrar una posible solución al problema que se plantea, nos gustaría ofrecer datos con respecto a la velocidad de articulación media de los dialectos del español, que parece ser un terreno menos explotado en la literatura.

\section{La velocidad de habla y de articulación: definición}

$\mathrm{Al}$ analizar el habla según aspectos temporales, normalmente diferenciamos y nos referimos a dos características: la velocidad de habla y la velocidad de articulación.

La velocidad de habla (en inglés, "speaking rate" o "speech rate") comprende todos los signos lingüísticos y no lingüísticos (como, por ejemplo, las pausas silenciosas) producidos durante la duración total del habla (Laver, 1994, citado por Gold, 2018). Se 


\section{Dorottya Kovács}

puede definir la velocidad de habla también como el número de elementos (como sonido, sílaba, palabra) realizados durante un tiempo dado, incluyendo las pausas.

$\mathrm{Al}$ contrario, la velocidad de articulación ("articulation rate") muestra la velocidad de la articulación de los sonidos (Gósy, 1997: 130), o sea, la velocidad de la producción de los signos lingüísticos, prestando atención solo al tiempo usado para la articulación (Bóna, 2016: 159; Kassai, 1993: 63). Así, la velocidad de articulación también significa el número de elementos (sonido, sílaba, palabra) realizados durante un tiempo dado, pero en este caso excluyendo las pausas y los titubeos (Voigt y Schüppert, 2013: 321; Sjons y Hörberg, 2016).

Como la definición de la velocidad de habla y la de la velocidad de articulación son semejantes, la forma de cálculo también es casi idéntica en ambos casos. En caso de la velocidad de habla, sumamos el número de los sonidos, sílabas o palabras realizados, y lo dividimos entre la duración total del habla, incluyendo la duración de las pausas también. Si necesitamos la cifra de la velocidad de articulación, también sumamos el número de los signos de habla (sonidos, sílabas, o palabras), pero lo dividimos entre la duración de la articulación, que es la duración total del habla menos la duración de las pausas. También podemos dividir el número de los signos de habla con la suma de las partes destinadas a la articulación misma, es decir, con la suma de las partes que encontramos entre las pausas (Bóna, 2016: 159; Bóna, 2014; Voigt y Schüppert, 2013: 324). Para mostrar estos dos tipos de velocidad, podemos utilizar varias medidas, como palabra/minuto, sílaba/minuto, sílaba/segundo o sonido/segundo (Gósy, 2004, citado por Bóna, 2016: 159).

El cambio y el control de la velocidad de habla y de articulación es muy difícil, especialmente en caso de habla espontánea (Gósy, 1997: 138; Gósy, 2004: 203). Sin embargo, la velocidad sí que cambia involuntariamente incluso dentro de un enunciado dado, así que podemos hablar de velocidad global, que se refiere al valor medio del habla total, pero también existe la velocidad local, que muestra el valor de solo una parte dada del habla total (McDougall, 2006, citado por Gold, 2018).

\section{Los factores que influyen en la velocidad de articulación}

Como nuestro análisis se centra en la velocidad de articulación, a continuación, presentaremos algunos factores que pueden influir en la velocidad de articulación. Subosits (1990: 159-160) determina dos tipos de estos factores: él habla de los factores internos (como características individuales del hablante) y externos (como el tema o la situación del habla).

En cuanto a los factores internos, cabe mencionar las emociones. Cuando, por ejemplo, estamos felices o enfadados, hablamos más rápidamente, mientras que la tristeza reduce la velocidad (Scherer 1995, citado por Bóna, 2007: 36, Bóna, 2016: 162 y Gocsál, 1999: 19). También es importante destacar la edad, porque en la niñez, durante los primeros años de la adquisición de la lengua materna, la velocidad es más lenta (Gósy, 1997: 134), pero durante la juventud, por el ritmo rápido de la vida, la velocidad 
La velocidad de articulación en la enseñanza de ELE

aumenta (Subosits, 1990: 161). Según Balázs (1993), la velocidad en la vejez otra vez va a ser más lenta. No obstante, tenemos que añadir que según los resultados de Quené (2008: 1109), la velocidad de articulación media no está influida por la edad del hablante en cuestión. Con respecto al sexo, encontramos resultados contradictorios en la literatura internacional (véanse, por ejemplo, Verhoeven et al., 2004, citado por Quené, 2008: 1104; Tuomainen y Hazan, 2016: 2107; Gósy, 1997, citado por Gocsál, 2001: 63). Con respecto a la lengua húngara, Gocsál (2001: 69-70) no encontró ninguna diferencia entre las mujeres y los varones.

Dentro de la categoría de los factores externos encontramos, por ejemplo, el estilo de habla. Según Bóna (2014 y 2013, citado por Bóna, 2016: 162), la lectura y la conversación son los estilos que cuentan con una velocidad más alta; y Markó (2005) determina la descripción de fotos como el estilo más lento. La diferencia entre la lectura y el habla espontánea se explica por el hecho de que, mientras leemos, presentamos ideas ya expresadas, pero en el caso del habla espontánea el hablante también tiene que planificar sus pensamientos (Gósy, 2004: 206). Además, las palabras que cuentan con significado las pronunciamos más lentamente que, por ejemplo, los artículos o adverbios (Hegedûs, 1957: 225; O’Shaughnessy, 1995, citado por Dankovicová, 1999: 272). La velocidad de habla y de articulación también depende de la lengua en cuestión (véase, por ejemplo, Horger, 1929: 29-30, citado por Hegedűs, 1957: 223-224), de la residencia u origen: los hablantes de una ciudad hablan más rápidamente que los hablantes de las provincias (Hegedűs, 1957: 223-224). Asimismo, debemos mencionar que cuanto más alto es nuestro nivel en la lengua dada, tanto más alta será nuestra velocidad de articulación (véase Trouvain y Möbius, 2014: 277-278, con respecto al alemán y el francés).

En la siguiente tabla se verán algunas cifras de velocidad de articulación encontradas en la literatura internacional, prestando atención solo a las lenguas húngara y española, y a los estilos de habla más cercanos a la entrevista, el estilo elegido por nosotros. Las fuentes de los datos se encuentran en una nota de pie.

\begin{tabular}{|c|c|c|c|}
\hline Lengua/Estilo & Sin especificar & (Medio)espontáneo & Conversación \\
\hline húngaro & $\begin{array}{l}\text { 12,5-14,0 sonidos/s [1] } \\
14,53 \text { sonidos/s (varones), } \\
14,32 \text { sonidos/s (mujeres) [2] } \\
\text { desde } 8,85 \text { sonidos/s hasta } \\
18,2 \text { sonidos } / \mathbf{s} \text { [1] } \\
14,2 \text { sonidos/s (hablantes de } \\
20-30 \text { años) [1] } \\
6 \text { sonidos/s ( } 3 \text { años), } 8 \\
\text { sonidos/s ( } 6 \text { años), 10,2 } \\
\text { sonidos/s (10 años) [3] }\end{array}$ & $\begin{array}{l}\text { 9-19 sonidos/s, 45-91 } \\
\text { palabras/p [3] } \\
4,9-6,9 \text { sílabas/s } \\
\text { (jóvenes), } 4,0-5,6 \\
\text { sílabas/s (mayores) [4] }\end{array}$ & $\begin{array}{l}\text { 4,7-7,0 } \\
\text { sílabas/s } \\
\text { (jóvenes), 4,0- } \\
\mathbf{5 , 6} \text { sílabas/s } \\
\text { (mayores) [4] }\end{array}$ \\
\hline
\end{tabular}

2 [1] Gósy, 2004: 205-206; [2] Gocsál 2001: 68; [3] Gósy, 1997: 132-134; [4] Bóna, 2014; [5] Wainschenker et al., 2002: 100; [6] Shrosbree, 2015; [7] Voigt y Schüppert, 2013: 322, 326-327. 


\begin{tabular}{|l|l|l|l|}
\hline $\begin{array}{l}\text { español } \\
\text { (europeo) }\end{array}$ & $\begin{array}{l}\mathbf{2 0 5} \text { palabras/min (mediados } \\
\text { del s. 20) [5] } \\
\mathbf{6 , 0 8} \text { sílabas/s [6] }\end{array}$ & $\begin{array}{l}\mathbf{6 , 5} \text { sílabas/s (basados } \\
\text { en la ortografía) [7] } \\
\mathbf{4 , 3 2} \text { sílabas/s [7] }\end{array}$ & \\
\hline $\begin{array}{l}\text { español } \\
\text { (argentino) }\end{array}$ & $\begin{array}{l}\mathbf{1 2 0 - 1 5 0} \text { palabras/min } \\
\text { (mediados del s. 20) [5] }\end{array}$ & & \\
\hline
\end{tabular}

Tabla 1. Velocidad de articulación del húngaro, del español europeo y argentino según investigaciones previas

\section{Las hipótesis}

En una investigación realizada a mediados del siglo XX, con respecto al español europeo, Navarro Tomás (1950, citado por Wainschenker et al., 2002: 100) determinó la velocidad media en 205 palabras/minuto. Unas décadas más tarde, Loprete (1984, citado por Wainschenker et al., 2002: 100) analizó el dialecto rioplatense y determinó la velocidad media en 120-150 palabras/minuto.

Basándonos en los datos presentados, suponemos que:

- en el estilo de habla semiespontáneo, la velocidad de articulación de los dialectos europeos es más alta que la velocidad de articulación de los dialectos americanos.

Según nuestra investigación ya mencionada (Kovács, 2019), los diez informantes (estudiantes de nivel B2) pudieron producir velocidades de habla y de articulación significativamente más lentas que las de un hablante nativo andaluz.

Detallando este fenómeno en la presente investigación, en este caso también suponemos que:

- los estudiantes que participaron en este análisis cuentan con una velocidad de articulación más lenta que la velocidad de articulación de todos los dialectos analizados.

\section{Corpus}

Como ya hemos mencionado, en esta investigación nos centramos en la comparación del habla de los estudiantes con la producción de hablantes nativos de cuatro dialectos del español. Para analizarlo, usamos un corpus de cincuenta muestras de audio auténticas (habla semiespontánea: entrevistas), diez grabaciones de informantes húngaros y cuarenta de hablantes nativos del español.

Los diez participantes de la investigación eran estudiantes universitarios, tenían entre 20 y 25 años (nacidos entre 1993 y 1997; nueve mujeres, un hombre), y hablaban el español a un nivel B2 (ya habían superado un examen de este nivel, pero todavía no uno de nivel C1) cuando grabamos las entrevistas.

Los hablantes nativos representan cuatro dialectos del español (diez personas de cada dialecto; cinco mujeres y cinco varones), todos actores. La edad media de los hablantes se encuentra en la Tabla 2: 
La velocidad de articulación en la enseñanza de ELE

\begin{tabular}{|l|l|l|}
\hline & Mujeres & Varones \\
\hline madrileño & 30,6 años & 39,6 años \\
\hline andaluz & 30,2 años & 38 años \\
\hline mexicano (nacidos en C. de México) & 33,4 años & 40 años \\
\hline $\begin{array}{l}\text { rioplatense (nacidos en la capital de } \\
\text { Argentina o de Uruguay) }\end{array}$ & 38 años & 43,6 años \\
\hline
\end{tabular}

Tabla 2. Edad de los informantes

Las entrevistas a los actores nativos del español las encontramos en una página web destinada a compartir vídeos, y los audios de los informantes húngaros los grabamos nosotros, en un aula vacía y silenciosa de una universidad, y los hablantes no recibieron ningún tipo de información sobre los objetivos de este trabajo. En cada caso, los estudiantes húngaros participaron en una entrevista con el mismo hablante nativo, y solo los dos miembros de la entrevista y el director de la investigación estaban en el aula.

\section{Metodología}

Tanto en el caso de los hablantes nativos del español, como en el caso de los estudiantes húngaros, elegimos las partes de las entrevistas en las que hablaban los informantes, y analizamos solo estos fragmentos. Tampoco prestamos atención a las pausas y titubeos, puesto que estas no forman parte de la velocidad de articulación. Todas las muestras de audio las analizamos en la versión 6.1.16 del programa fonéticoacústico Praat (Boersma y Weenink, 2020).

Para calcular la velocidad de articulación, en el programa Praat segmentamos y anotamos las grabaciones, separamos las pausas y añadimos transcripciones a las partes entre las pausas, o sea, a las partes de producción de habla (Gósy y Menyhárt eds., 2003: 295, citado por Bóna, 2007: 17). Según los datos de la literatura, consideramos las partes silenciosas de al menos 200 milisegundos de duración como pausas (Shrosbree, 2015; Goldman-Eisler, 1973, y Guaitella, 1996, citados por Blondet, 2001: 8; Gósy, 1997: 133). Basándonos en Bóna (2009: 11), en cada caso transcribimos el habla casi fonéticamente, o sea, con transcripción fonética simplificada. Solo transcribimos los sonidos realizados (Bóna, 2005; Koreman, 2006, citado por Bóna, 2014). Para evitar el uso de los dígrafos como "ll" o "ch", usamos los caracteres fonémicos del Alfabeto Fonético Internacional (AFI) para la anotación. 


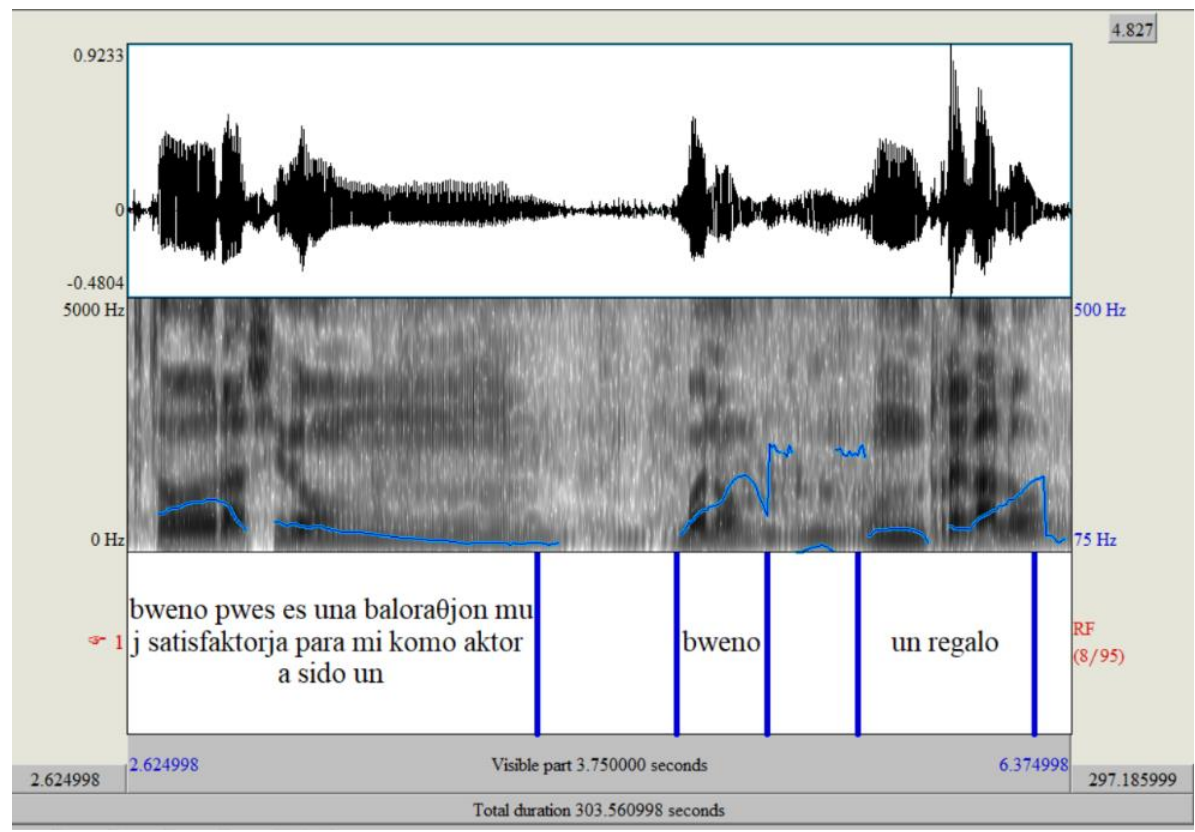

Figura 1. Segmentación y anotación en el programa Praat

En caso de calcular la velocidad de habla y la velocidad de articulación, la unidad de medida elegida tiene un papel fundamental. Las varias unidades de medida posibles ya presentadas (por ejemplo, palabra/minuto, sílaba/segundo, sonido/segundo) cuentan con ventajas y desventajas también, por esta razón es importante elegir la medida más relevante con respecto a nuestros fines. La unidad palabra/minuto puede ser problemática si encontramos palabras solo parcialmente realizadas (Bóna, 2007: 11), y si elegimos la unidad sonido/segundo, la anotación de habla rápida será casi imposible (Bóna, 2007: 12). Partiendo de estos argumentos, elegimos la unidad sílaba/segundo, porque así es más fácil anotar el habla rápida (Bóna, 2007: 16), y puede ser una solución a las palabras parcial o impropiamente realizadas (Bóna, 2007: 11).

Como la velocidad de articulación significa la velocidad de la producción de signos lingüísticos (Gósy, 2004: 203-204), podemos calcularla de la siguiente manera: de la duración total de habla restamos la duración de las pausas y de los titubeos, y con esto dividimos el número de las sílabas realizadas (Gyarmathy et al., 2016: 9). También es posible sumar la duración de la producción de los signos lingüísticos, y con esto dividimos el número de las sílabas (Gósy, 2004: 204). Para los cálculos nosotros usamos un script (diseñado por Márton Bartók), que es un programa complementario de Praat. Este script calculó automáticamente la duración de los segmentos que nosotros habíamos anotado, y guardó los datos en una hoja de cálculo Excel. Así, nos resultó más fácil sumar la duración de la producción de los signos lingüísticos. 
La velocidad de articulación en la enseñanza de ELE

\section{Los resultados}

Según nuestra primera hipótesis, los dialectos europeos del español (madrileño y andaluz, en nuestro caso) cuentan con una velocidad de articulación media más alta que los dialectos americanos analizados por nosotros (mexicano y rioplatense).

En la Tabla 3 se encuentran nuestros resultados; la velocidad de articulación siempre aparece en sílabas/segundo.

\begin{tabular}{|l|l|l|l|l|l|l|l|}
\hline \multicolumn{2}{|c|}{ Madrileño } & \multicolumn{3}{c|}{ Andaluz } & \multicolumn{2}{c|}{ Mexicano } & \multicolumn{2}{c|}{ Rioplatense } \\
\hline Informante & $\begin{array}{c}\text { VA } \\
\text { (síl/s) }\end{array}$ & Informante & VA & Informante & VA & Informante & VA \\
\hline EE & 6,16 & AV & 6,32 & AB & 6,27 & AT & 5,96 \\
\hline EF & 5,95 & BC & 6,86 & AD & 7,28 & AV & 5,75 \\
\hline FT & 5,36 & DR & 7,03 & AR & 5,5 & BA & 6,86 \\
\hline LM & 6,03 & IC & 6,07 & CA & 6,45 & DR & 7 \\
\hline MA & 6,13 & JM & 7,33 & FC & 6,6 & FA & 6,04 \\
\hline MP & 5,49 & MC & 6,82 & GG & 6,18 & MM & 5,6 \\
\hline NM & 6,49 & MD & 6,5 & JPM & 7,14 & NO & 6,49 \\
\hline PO & 6,71 & MR & 6,25 & LH & 6,26 & PW & 5,78 \\
\hline RF & 6,75 & MS & 5,35 & MP & 6,57 & SR & 6,12 \\
\hline SM & 6,06 & NM & 5,7 & MR & 6,41 & VO & 6,55 \\
\hline MEDIO & $\mathbf{6 , 1 1}$ & MEDIO & $\mathbf{6 , 4 2}$ & MEDIO & $\mathbf{6 , 4 7}$ & MEDIO & $\mathbf{6 , 2 2}$ \\
\hline DESVIAC. & $\mathbf{0 , 4 6}$ & DESVIAC. & $\mathbf{0 , 6 1}$ & DESVIAC. & $\mathbf{0 , 5}$ & DESVIAC. & $\mathbf{0 , 4 8}$ \\
\hline
\end{tabular}

Tabla 3. Velocidad de articulación en los cuatro dialectos españoles analizados

Como vemos, la velocidad de articulación media del dialecto madrileño (a partir de diez informantes) es de 6,11 sílabas/segundo, la del dialecto andaluz es de 6,42 sílabas/segundo, mientras que la velocidad de articulación del español mexicano es de 6,47 sílabas/segundo y del rioplatense es de 6,22 sílabas/segundo. Basándonos en estas cifras, podemos afirmar que nuestra primera hipótesis no queda confirmada, puesto que el dialecto mexicano cuenta con la velocidad de articulación más alta, y el español madrileño parece ser el dialecto más lento.

Sin embargo, debemos destacar que no hallamos una diferencia considerable entre los dialectos, o sea, el español mexicano (el dialecto más rápido) resulta tener una velocidad de articulación un 5,6\% más alta que el dialecto más lento, el madrileño.

Según nuestra segunda hipótesis, todos los estudiantes húngaros de nivel B2 tienen una velocidad de articulación más lenta que los cuatro dialectos analizados en esta investigación. Para comprobar tal hipótesis, veamos los resultados de la Tabla 4. 


\begin{tabular}{|c|c|c|c|}
\hline \multicolumn{2}{|c|}{ Informantes húngaros } & \multicolumn{2}{|c|}{ Hablantes nativos } \\
\hline Informante & $\begin{array}{l}\text { Velocidad de } \\
\text { artic. (síl/s) }\end{array}$ & Dialecto & $\begin{array}{c}\text { VA cifra } \\
\text { media (síl/s) }\end{array}$ \\
\hline 01_B2 & 3,64 & Madrileño & 6,11 \\
\hline 02_B2 & 4,81 & Andaluz & 6,43 \\
\hline 03_B2 & 4,27 & Mexicano & 6,47 \\
\hline 04_B2 & 3,89 & Rioplatense & 6,22 \\
\hline 05_B2 & 4,25 & & \\
\hline 06_B2 & 4,74 & & \\
\hline 07_B2 & 5,46 & & \\
\hline 08_B2 & 5,78 & & \\
\hline 09_B2 & 4,95 & & \\
\hline 10_B2 & 4,13 & & \\
\hline MEDIO & 4,59 & & \\
\hline DESVIACIÓN & 0,68 & & \\
\hline
\end{tabular}

Tabla 4. Velocidad de articulación de los estudiantes húngaros

En esta tabla vemos que los estudiantes húngaros analizados producen una velocidad de articulación media (al hablar español semiespontáneo) de 4,57 sílabas/segundo. Esta cifra es considerablemente menor que la cifra de cualquier dialecto del español investigado: el dialecto del español más lento, el madrileño, tiene una velocidad un $25 \%$ más alta. También podemos notar a partir de los datos que ninguno de los hablantes húngaros alcanza la velocidad de articulación media de un dialecto del español. Así, nuestra segunda hipótesis queda confirmada.

\section{Discusión y conclusión}

En esta investigación analizamos la velocidad de articulación de hablantes nativos del español (representantes de cuatro dialectos) y la velocidad de articulación de estudiantes hungaroparlantes de nivel B2 (MCER). Después de una introducción teórica y de la presentación de nuestro corpus y nuestra metodología, detallamos nuestros resultados.

Los datos obtenidos muestran que el dialecto mexicano resulta ser el más rápido, y el español madrileño, el más lento. Esto contradice las investigaciones anteriores (Navarro Tomás, 1950 y Loprete, 1984, citados por Wainschenker et al., 2002: 100). Sin embargo, nosotros tampoco encontramos diferencia significativa entre los dialectos del español.

Por otra parte, también investigamos la velocidad de articulación de estudiantes húngaros de español, y la comparamos con los valores de los nativos. Vimos que ninguno de los estudiantes alcanzó el valor medio de cualquier dialecto del español. Además, la cifra media de los húngaros es significativamente más lenta (un 25\%) que el valor medio del madrileño, el dialecto más lento, según nuestro análisis. 
La velocidad de articulación en la enseñanza de ELE

Aunque nuestros datos no permiten tratar nuestros resultados como representativos (porque trabajamos con solo diez hablantes de cada lengua o dialecto), pensamos que la comparación de los diferentes dialectos del español con respecto a las características temporales parece ser un terreno que ofrece mucha información pero que está muy poco explotada, así que valdría la pena llevar a cabo más investigaciones en este tema. Además, basándonos en nuestros datos, decimos que se debería prestar mucha más atención al desarrollo de las competencias comunicativas en la enseñanza de ELE, puesto que los alumnos del español ni en el nivel B2 son capaces de producir enunciados orales que cuenten con características temporales o con una velocidad semejante a la producción media de la lengua meta. Esto, puede resultar una desventaja para los alumnos del español, porque, según los resultados de la investigación de Mátraházi (en prensa), con respecto a la fluidez, los profesores españoles dan menos puntos a la producción de estudiantes húngaros del español (de nivel B2) que los profesores húngaros. El factor que más influye en la evaluación de los profesores húngaros es el sistema de pausas, mientras que en el caso de los profesores españoles, la velocidad de habla y la velocidad de articulación también son factores importantes.
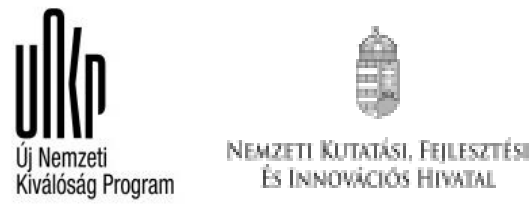

\section{Referencias bibliográficas}

Baditzné Pálvölgyi, Kata (2014). ¿Cómo logro que mis alumnos conversen con espontaneidad en español en un contexto no hispanohablante?. En: Izquierdo, J. M. (ed.). V Congreso Internacional de FIAPE: ¿Qué español enseñar y cómo? V ariedades del español y su enseñanza. Jornadas Pedagógicas. Ministerio de Educación y Cultura. Madrid. 1-9. Asequible en: https://www.educacionyfp.gob.es/dam/jcr:62944178-5b09-4487-b94b$525380 \mathrm{fba} 58 \mathrm{e} / 1$--como-logro-que-mis-alumnos-conversen-con-espontaneidad-enespanol-en-un-contexto-no-hispanohablante--palvolgyikata-pdf.pdf, fecha de consulta: 8-11-2020.

Baditzné Pálvölgyi, Kata (2019). ¿Debería importarnos la pronunciación en la enseñanza del español con fines específicos? Lingua. Budapest: Budapesti Corvinus Egyetem Corvinus Idegennyelvi Oktató- és Kutatóközpont. 232-243. Asequible en: http://www.risk-conference.uni-corvinus.hu/fileadmin/user_upload/hu/tanszekek/ tarsadalomtudomanyi/iok/files/konferencia_koetet_2018.pdf, fecha de consulta: 8-112020. 


\section{Dorottya Kovács}

Baditzné Pálvölgyi, Kata - Gaál, Zoltán Kristóf - Hegedüs, Renáta - Kovács, Dorottya - Poller, Lilla - Takács, Lili (2019). Nyelvhelyesség vagy érthetőség?: Magyar anyanyelvű nyelvtanulók beszédproduktumainak megítélése spanyoltanári szemmel. MODERN NYELVOKTATÁS, 25(1). 29-38. Asequible en: https://epa.oszk.hu /03100/03139/00038/pdf/EPA03139_modern_nyelvoktatas_2019_01_029-038.pdf, fecha de consulta: 9-11-2020.

Balázs, Boglárka (1993). Az időskori hangképzés jellemzői. Beszédkutatás '93. 156-165. DOI: 10.18425/FONOLV.2016.02. Asequible en: http://real-j.mtak.hu/4672/, fecha de consulta: 8-11-2020.

Blondet S., María Alejandra (2001). Las pausas llenas: marcas de duda e identidad lingüística. Lingua Americana, 5(8). 5-15. Asequible en: https://produccioncientificaluz.org /index.php/lingua/article/view/17077, fecha de consulta: 10-11-2020.

Boersma, Paul - Weenink, David (2020). Praat: doing phonetics by computer [programa informático]. Versión 6.1.16. Asequible en: http://www.praat.org/, fecha de consulta: 9-11-2020.

Bóna, Judit (2005). A hadaró és a gyors beszéd temporális sajátosságai. Magyar nyelvôrr, 129(2). 235-242. Asequible en: http://epa.oszk.hu/00100/00188/00038/pdf/129209.pdf, fecha de consulta: 10-11-2020.

Bóna, Judit (2007). A felgyorsult beszéd produkciós és percepciós sajátosságai. (Tesis doctoral). Asequible en: http://doktori.btk.elte.hu/lingv/bona/Phd_dolgozat_BonaJudit.pdf, fecha de consulta: 10-11-2020.

Bóna, Judit (2009). A gyors beszéd. Budapest: Lexica Kiadó y Magyar Tudományos Akadémia Könyvtára.

Bóna, Judit (2014). Temporal characteristics of speech: The effect of age and speech style. The Journal of the Acoustical Society of America, 136(2). 116-121. DOI: 10.1121/1.4885482. Asequible en: https://asa.scitation.org/doi/abs/10.1121/1.4885482, fecha de consulta: 8-11-2020.

Bóna, Judit (2016). Temporális sajátosságok a beszédben. En: Bóna, J. (ed.). Fonetikai olvasókönyv. 159-173. Budapest: ELTE Fonetikai Tanszék. DOI: 10.18425/FONOLV.2016.13. Asequible en: http://real.mtak.hu/41368/, fecha de consulta: 9-11-2020.

Dankovicová, Jana (1999). Articulation Rate Variation within the Intonation Phrase in Czech and English. Phonetic sciences. 269-272. Asequible en: https://www.inter nationalphoneticassociation.org/icphs-proceedings/ICPhS1999/papers/p14_0269.pdf, fecha de consulta: 10-11-2020.

Gocsál, Ákos (1999). Egyéni különbségek az artikulációs tempó percepciójában. Beszédkutatás '99. 19-29. Asequible en: http://real-j.mtak.hu/4686/, fecha de consulta: 9-11-2020. 
La velocidad de articulación en la enseñanza de ELE

Gocsál, Ákos (2001). Gyorsabban beszélnek-e a nők, mint a férfiak? Beszédkutatás 2001. 61-72. Asequible en: http://real-j.mtak.hu/4688/, fecha de consulta: 8-11-2020.

Gold, Erica (2018). Articulation Rate as a Speaker Discriminant in British English. Proc. Interspeech 2018. 1828-1832. DOI: 10.21437/Interspeech.2018-1384. Asequible en: https://www.researchgate.net/publication/325650762_Articulation_Rate_as_a_Speake r_Discriminant_in_British_English, fecha de consulta: 10-11-2020.

Gósy, Mária (1997). A magyar beszéd tempója és a beszédmegértés. Magyar Nyelvôr, 121 (2). 129-139. Asequible en: http://real-j.mtak.hu/6071/1/MagyarNyelvor_1997.pdf, fecha de consulta: 8-11-2020.

Gósy, Mária (2004). Fonetika, a beszéd tudománya. Budapest: Osiris Kiadó.

Gyarmathy, Dorottya - Auszmann, Anita - Neuberger, Tilda (2016). Az anyanyelvi és az idegen nyelvi spontán beszéd temporális jellemzői. Anyanyelv-pedagógia, 9(1). 5-19. DOI: 10.21030/anyp.2016.1. Asequible en: http://www.anyanyelv-pedagogia.hu/cikkek. php?id=609, fecha de consulta: 10-11-2020.

Hegedűs, Lajos (1957). Beszédtempó-elemzések. Magyar nyelvốr, 81(1). 223-227. Asequible en: http://real-j.mtak.hu/6044/1/MagyarNyelvor_1957.pdf, fecha de consulta: 8-11-2020.

Hegedüs, Renáta (2019). Tanárnö, mikor beszélgetünk a robottal?: Szorongásoldás kiskamasz. korban idegennyelv órán a mesterséges intelligencia segítségével. Trabajo presentado en la Conferencia Nacional de Asociaciones de Estudiantes Científicos. Budapest: Eötvös Loránd Tudományegyetem.

Kassai, Ilona (1993). Gyorsult-e a magyar beszéd tempója az elmúlt 100-120 évben? Beszédkutatás '93. 62-69. Asequible en: http://real-j.mtak.hu/4672/, fecha de consulta: 10-11-2020.

Kovács, Dorottya (2019). La velocidad de habla de los hungaroparlantes al hablar español espontáneo. Trabajo presentado en la Conferencia Nacional de Asociaciones de Estudiantes Científicos. Budapest: Eötvös Loránd Tudományegyetem.

Markó, Alexandra (2005). A spontán beszéd nébány szupraszegmentális jellegzetessége. (Tesis doctoral). Asequible en: http://www.spontanbeszed.hu/letoltes/aspontanbeszed szuprasz.pdf, fecha de consulta: 9-11-2020.

Mátraházi, N. (en prensa). Eltérö nyelvi hátterü hallgatók beszédfolyamatosság-értékelése magyar és spanyol beszéd alapján. 14 ${ }^{\mathrm{a}}$ Conferencia para Doctorandos de Lingüística Aplicada, $07 / 02 / 2020$.

Ministerio de Educación, Cultura y Deporte (2002). Marco Común Europeo de Referencia para las lenguas: Aprendizaje, Enseñanza, Evaluación. Asequible en: https://cvc.cervantes.es /ensenanza/biblioteca_ele/marco/cvc_mer.pdf, fecha de consulta: 10-11-2020. 
Quené, Hugo (2008). Multilevel modeling of between-speaker and within-speaker variation in spontaneous speech tempo. The Journal of the Acoustical Society of America, 123(2). 1104-1113. DOI: 10.1121/1.2821762.

Shrosbree, Miki (2015). Cross-Linguistic Articulation Rate among Near-Balanced Bilinguals and Implications for Second Language Fluency Measurement. 18th International Congress of Phonetic Sciences. Glasgow (Reino Unido). Asequible en: https://www.international phoneticassociation.org/icphs-proceedings/ICPhS2015/Papers/ICPHS0572.pdf, fecha de consulta: 8-11-2020.

Sjons, Johan - Hörberg, Thomas (2016). Articulation rate in child-directed speech increases as a function of child age. Fonetik 2016. Stockholm (Suecia). Asequible en: https://www.researchgate.net/publication/304676516_Articulation_rate_in_childdirected_speech_increases_as_a_function_of_child_age, fecha de consulta: 9-11-2020.

Subosits, István (1990). Adatok az életkor és a beszédtempó összefüggéséhez egy eszközfonetikai vizsgálat alapján. En: Földi, É. (ed.). Egyetemi Fonetikai Füretek 3. 159167. Budapest: ELTE BTK Fonetikai Tanszék. Asequible en: https://edit.elte.hu /xmlui/handle/10831/10651 ?show=full, fecha de consulta: 8-11-2020.

Trouvain, Jürgen - Möbius, Bernd (2014). Sources of variation of articulation rate in native and non-native speech: comparisons of French and German. Speech Prosody 2014. 275-279. DOI: 10.21437/SpeechProsody.2014-42. Asequible en:

https://www.researchgate.net/publication/262723047_Sources_of_variation_of_articu lation_rate_in_native_and_non-native_speech_Comparisons_of_French_and_German, fecha de consulta: 8-11-2020.

Tuomainen, Outi - Hazan, Valerie (2016). Articulation rate in adverse listening conditions in younger and older adults. INTERSPEECH 2016. 2105-2109. DOI: 10.21437/Interspeech.2016-843. Asequible en: https://www.researchgate.net/publication /307889418_Articulation_Rate_in_Adverse_Listening_Conditions_in_Younger_and_Ol der_Adults, fecha de consulta: 10-11-2020.

Voigt, Stefanie - Schüppert, Anja (2013). Articulation rate and syllable reduction in Spanish and Portuguese. In: Gooskens, Van Bezooijen, C. R. (Eds.). Phonetics in Europe: Perception and Production. 317-332. DOI: https://doi.org/10.3726/978-3-653-03517-9. Asequible en: http://www.let.rug.nl/gooskens/project/pdf/Voigt $\% 20 \& \% 20$ Schueppert \%20(2013).pdf, fecha de consulta: 8-11-2020.

Wainschenker, Rubén - Doorn, Jorge - Castro, Marcela (2002). Medición Cuantitativa de la Velocidad del Habla. Procesamiento del Lenguaje Natural, 28. 99-104. Asequible en: http://journal.sepln.org/sepln/ojs/ojs/index.php/pln/article/view/3308, fecha de consulta: 10-11-2020. 